\title{
進一步開展西北地區科㼂研究工作 刍祖國社會主戔建設事策服務
}

\author{
一在中國科學院西北分院籌備委員會成立大會上的 \\ 報告（1954 年7月16日）
}

張 德 生

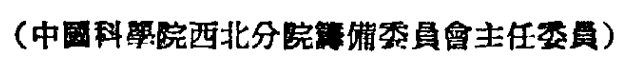

中國科學院唒北分院管借委員會今天成立,

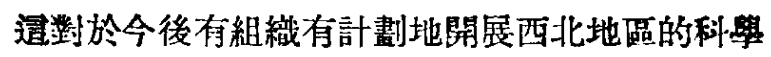
研究工作是有重大意義的。

大家知这，我們國家目前正處在㼛會主義建 設和社會主義改造的過渡時期。在造侗過渡時期 內, 我椚國家的總任務就是逐步貫現國家的社會 主義工業化, 逐步完成對農業、手工業和資本主 義工商業的社會主義改造, 把我門的祖國建設成 第一個偉大的、幸福的、富强的社會主義國家。 從 1953 年起, 我們國家已經開始保施第一调國家

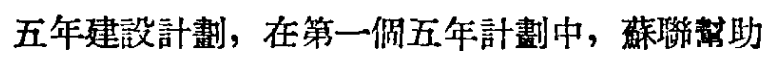
我國建設的 141 項巨大企業中有訐多分扸在西

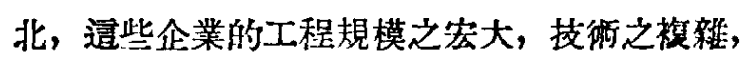
都是空前的。此外, 我椚遥要相應地發展西北地

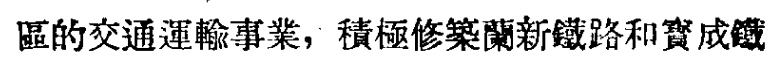
路, 並皘極淮借興修包蘭鐵路, 以及修築詐多重

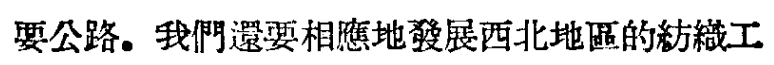
業以及人民生活所迫切需要的地方工業。我椚也 還要相鷹地發展西北地區的農業、畜牧業、森林 業以及文化、敉育和衛生事業。而所有這些國家 建設事業的發展, 又都不能離開科學事業的相應 弡展, 因䉆没有發達的科學事業, 就不可能有工 農業生產技術水平的進一步提高, 就不可能有 各项建設事業的迅速前進。科學工作對國家建設 事業是具有重要意義的。自然, 没有發達的工業 和農業, 科學事業要蒦得祉勃的發展也是不可能 的。這兩者的關係, 就是說國家建設與科學事業
的關保, 正如中國科學院郭沐若院带在“關於中 國利署院的基本情况和今後工作任務的報告”中 所說的: “沒有科技術的不断支援和科事業 的相㮣發展, 要完成國家䇃會主義工業化的任䅂 是不可能的; 反之, 蜼開了棈極支援國家建設的

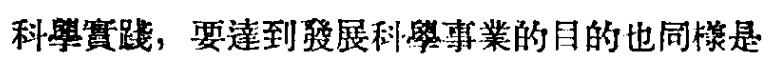
不可能的。”

西北地區的自然條件是非常渗越的。西北地 區的面積, 佔全國三分之一。在這地透潤廣大的 土地上，程藏着瞣富的地上和地下資源。在破藏 方面, 西自新融, 東至莍北的廣大地區内, 有着 許多藏量非常䁷富的储油粠造, 喍的储藏量在全 國也佔着很重要的位睘; 有色金犀、贵重金屬以 及窗贵的建築村料等, 發現的也很多。在晨林蓄 牧方面, 西北是全國棉花生產的一僻重要地區。 新疆的棉花生産有着廣潤的發展園地, 關中本原 的小麥在全國小麥生產上佔有重要位置; 西北的 青牧業在全國更是佔着很大的比重。西北地區還 有着許多廣潤肥沃的荒地和草原, 有着許多宜於 造林的山川。西北也是水力資源很嗐富的地區, 水力墢電和灌溉事業有着無限的墢展前途。西北 自然資源的潛在力是無等的, 西北自然科盟工作 者的園地是無限宽廣的。随着祖國建設事業的穭 步弡展, 許多重要的複雜的科學問題的解决也日 見迫切, 例如工業方面的資源勘查、地震烈度测 定等問題; 農業方面的水土保持、土壤和農作物 品種的改良以及和自然災害作閏争等間題，青 
牧方面的牧草研究、音種改良和牲湆疫病防治等 問題, 都急需我捫科學工作者着手研究, 求得解 决。

全國解放以來，西北地區科學工作者在黨和 人民政府的關情和領導下，辛勤努力, 作了不少 工作，獲得了一定成曙。在石油、有色金屬、蝶 炭、水力等重要資嫄的勘查和研究工作方面，已

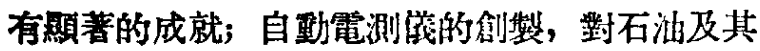

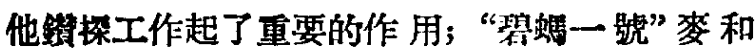
"6028”麥传良品種的培育與推廣, 提高了小麥的 库量; 水土保持站的建立, 受到蕫衆的熱烈歡迎, 取得了可贵的經驗; 跑豆象防治的成功, 扮縣梨 不結果問題以及小麥吸㡜路害的初步解决, 促進

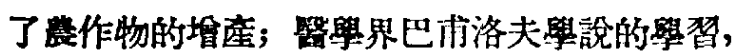
大大推進了對於先進醫學理論的研究; 三球儀的

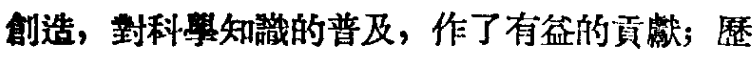
史文物的搜集與研究，給考古科學提供了很有價

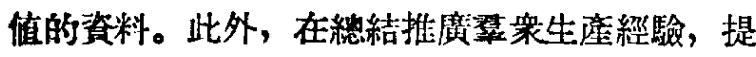

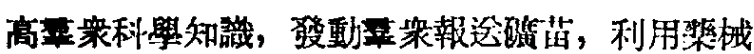
嘠勝自然災害, 防治牲畜疫病以及培秦青年科學 幹部等等方面, 也都做了不少工作。䋐年爽西北

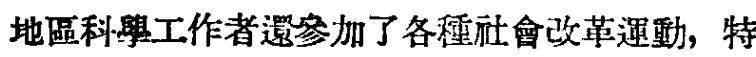
别是思想改造運動，影著地提高了自己的政治思 想水平。通些都笏今後進一步開展西北地政科學 研究工作, 支援國家建設㓣造了有利條件。但是,

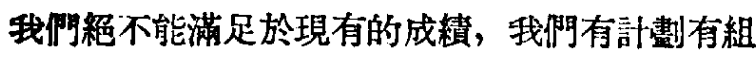

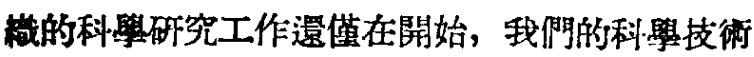
水平還遠遠落後於國家建設事業的發展, 我門的 科悬力量還遠不能道應國家建設事業的需要, 我 荫谴有 $90 \%$ 以上的地區没有經過系梳的跑查，連 最基本的科祭資料也没有。所有䄐一切, 就給牫 們賞前國家的建設事業造成了不少的困難，我們 每一個科學工作者都有貢任來勘助或家克服這些 困嚾, 來助解决當前國家建設中迫切需要解决

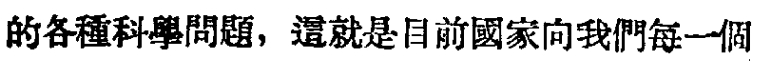
科作者提出的光榮和鴙巨的任移。

- 在過去國民黨統治的社會裹，科罢工作者没 有進行利學研究工作的自由和佟件, 因此他們也 就不可能在科學事業上創造出更大的成綘。而在 今天，我門國家传越的人民䟚主制度，篮科學事業 的墢屡開閩了廣涚的前途。“中華人民共和國憲法 草案”第 95 修規定了“中華人民共和或保障公民
進行科䑁研究、文學藝術佮作和其他文化活動的 自由。國家對於從事科學、敉育、文䁷、㙯術和 其他文化事業的公民的創造性工作, 給以鼓和和 助。”這就說明在我椚國家震, 任何一侗科鼻工 作者, 都有可能亚且應該在科學戰綖上第國家和

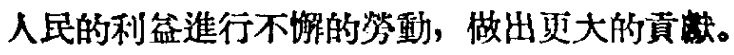

第了適應西北地區國家建設事業的需要, 中 國利咸院決定成立西北分院簿借機構, 蓝逐步建

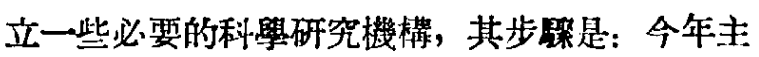
要是在西安成立西北分院簿供處亚開始箔備農業 生物研究所 (將中國利的院植物研究所西北工作

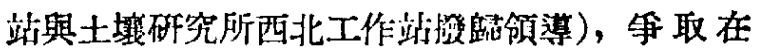

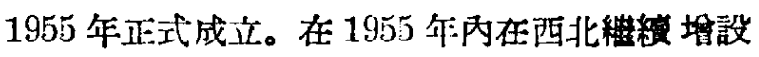
地震台站, 侯條作成熟後, 在闌州成立西北觀象 台。同時, 在蘭州筑建工業化學研究所, 在新疆 籌建以農業、資源調查與少数纪族語言研究第主 要任務的綜合研究所。這何假研究所均争取在 1956 年後牛年正式成立。此外, 考古研究所將在 西北筇設考古工作站。

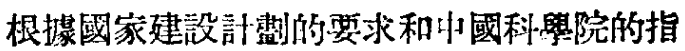
示, 中國科罢院西北分院簿備委員會的工作方針 應該是: 密切配合西北地區國家建設計劃, 組織 西北地剾的科學力量, 培蓄科學研究人材, 有重

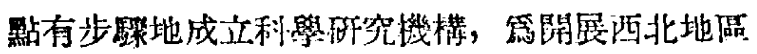
科學研究工作，積極创造條件。根㨜避一才針， 中國科學院西北分院箁備委县會在今後一個時期 的具體任称應該是:

（一）配合西北工業發展, 淮行唡域性自然 條件與資激的調枩研究工作, 逐步開展有關液體 败料及其他工業化酠方酥的科學研究工作。在進 行區域性自然保件與資源何调枯中, 要注意皘累 科學資料和整理研究現有所次料, 以便篇西北工

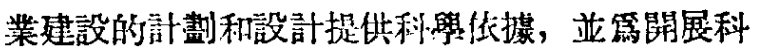
學研究工作㓣造必要的條件。關於開展液䯏然料 及其他工業化㼂方面的科學研究工作, 必須在最

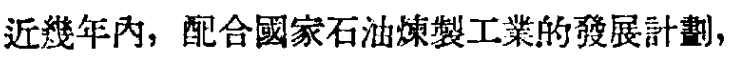
有步殷地進行。

（二）配合西北農、林、水利及音牧事業的 㗔展, 以黃河中上游水土保持問題篇中心, 淮行 称合性的調查研究。黄河中上游的黄土地带, 由 於土質、地形、雨量等的自然條件及歷史上溜耕、

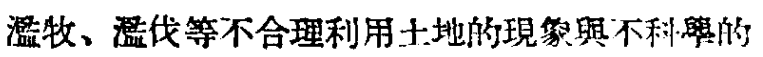


耗作方法, 使天然森林及優良的植物被婹受到很 大破壞，並使水土嚴重流失，根據現有資料，平 均每年約相當於 1 億 5 千萬酷農田被泔去表土 1 厘米, 其結果, 不僅隇低了土壤肥力, 影響了氣 侯, 並使大量泥沙流入黄河, 造成黄河下游的洪 水災害, 影響了黃河水力資源的充分利用。因此, 研究和解决黄河中上游的水土保持問題, 並圍繞 逜一研究工作進行農、林、牧和水利等的綜合性 的調查研究工作, 就成黨西北科學研究工作的一 項重要任務。研究這一問題的目的, 一方面是篇 解决黄河的泥沙問題提供科學传據, 從而解决鱼 河的洽本、水力資源利用、萑溉、航運等問題; 另一方面, 是第綜合性的合理的農業耕作制度提

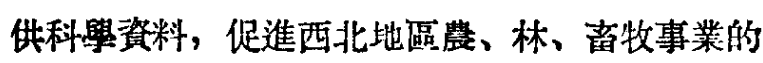
桴展。

（三）配合建設事業的發屡，進行歴史文物和 考古的利學調查政究工作, 以及開展西北地剾少 數民族的語言、文字、社會情况和風俗㕷慣等的 調查研究工作。開屡這些工作，在西北是有良好 的佟件和重要意義的, 均應注意積極進行。

這些任務是光榮而哏䤠的，我們西北地區的 科學工作者除了做好本身業務外，㮣該積極地參 加上迅有關的科學政究工作，協助中國科學院西 北分院篣倩委員會來完成這些任䅂。

篇了順利完成上述任務，我們必須注意和解 决以下幾偑問題:

（一）組䋨西北地區現有的科學力量和大力 培苓新的利學研究人材。這菨首先必須根據工作 的霹要和可能的條件，有步祭地加强和古實利學 研究機構，分別吸收各方䤄的科學工作者策任或 專任科學研究機構的工作。窟此，對西北地區現 有科學力量加以全面的調查和了解, 逐步而又積 極地和各方矿的科學工作者及其所在的學校、企 莱、機關建立經常的聯系, 還是完全必要的。在這 方面，我們希望能得到中華全國自然科學専門舉 會聯合會及各專門學會的積極協助。培䓹新的科 悬力量問題, 必須從粆方面積極進行。第一、請求 中央逐年給酉北調配一批研究生。第二、逐年在 西北各省選拔一批在科學矿究方面有發展前途的

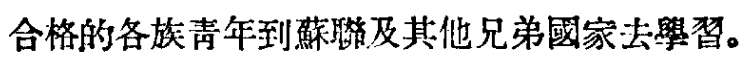
第三、利用假期或其他機會, 組織高等學校理、工、

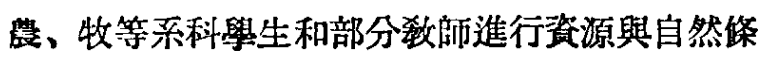

件調查，以資實㕷提滈。第四、特别要求我們的 老科學家應當把培䓹青年一代的科學人材看作自 己對國家對人民的一項重要任務, 熱情地笔無保 留地把自己的一切經驗、知識和研究成果傳授給 青年一代，並指導他們進行研究工作。

（二）軴立理論聯系賽際的工作作風。我們許 多科學工作者已經認識到理論必須與實際密切結 合, 並巨開始朝着咳個方向努力。但還有一些人 脫離了貫際情况, 片面强調研究高深理諭問題, 甚至涊第解决目前生産上的問題, 不能算是科學;

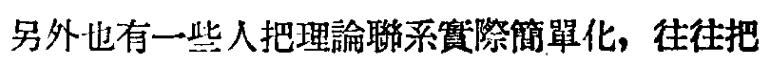
“實際”理解第只是純粹的直接的生産任務。道雨 種偏向都是不對的。正確的態度應該是一方面要 努力提高自己的學術理論水本, 另一方面又要密 切結合支援國家建設的利翼實践, 参與具體地解 决國家建設中的各項科學問題。這樣，把科学理 綸作第我們䂯究解决當前國家建設中利學問題的 指南, 又反過來, 通過歰儅前國家建設中科學問

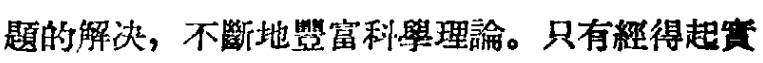
践的考驗, 又能瑟助筫践, 用貿践來检查自己的 理論的利學，才是真正的科學。同時，也只有在 理論指導下的實践, 书是有方向的實践, 而只有 還樣的惯践，才有其迅速提高與發展的前途。因 此，一切科學工作者都應融率勤地刻苦地鑽研科 㬴理論, 同時棈極地參加各項科的的践。在樹 立理論聯系暂際的作風中，一方面必須重泊䂥究

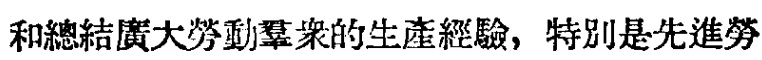
動者的刢造和發明; 另一方面, 科學研究的成果, 應該加以普及, 使能第廣大勞動釷䇋所学握, 以

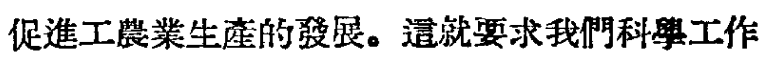

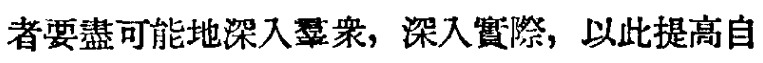

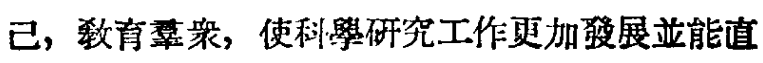
接服移於當前國家建設的需要。

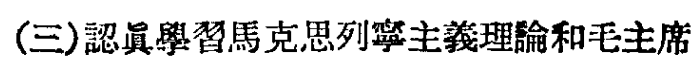
的著作，學㚙蘇聯先進的科學理論和方法。馬克 思列蜜主義理論不僅是關於形會發展規律的科 學，同時也是關於自然發展規律的科學。離開了 馬克思列繁主義讋登唯物論指導的科學, 就是没 有靈魂的科學; 而科學研究工作者一旦掌据了馬 克思列寧主義的裙證唯物論, 就會給他的科學研

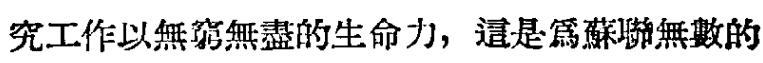
偉大科學家的偉大成就的事賽所登明了的。毛主 
席的著作，是馬克思列案主義理論結合中國革命 具體實践的科學諭著，是指導中國革命取得勝利 亚繼縝向着社會主蓄勝利前進的有力试器。作爲 現代中國的科學工作者，在其篇垌國過渡到社會

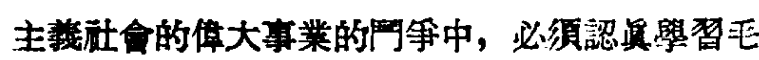
主席的著作，以求改造自己，提高自己。蘇聯的 科悬是世界上最先進的科學，蘇聯第一個原子能 福電站的建成，有力地說明蘇聯科學的高度水平。 毛主席指示說: “我何要進行偉大的國家建設, 我 們面前的工作是鞎苦的，我椚的經驗是不够的，

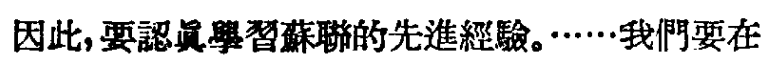
全國範圆內掀起學㚙蘇聯的高潮, 來建設我們的 國家。”我椚應該审記並在實践中切實執行毛主席 的指示, 努力學㕷蘇聯的科學理論, 我們還應該 毣習蘚聯科學工作者那種不怕困難的工作精神, 那種認员筇留的工作態度和賴事求是的工作作 夙，來提高我門的修䓹，更好地發揮自己的力量。

(四)科悬工作者應當在中國共圱黨和中央人 民政府的領導下, 親密葍結, 第祖國社會主莪建 設事業而共同努力。我們的黨一问是重親科學工 作, 重視知識分子的作用的, 這在中國人民民主 革命鬥爭中和勝利後國家建設事業迅速發展的厢 史事宾中, 已經得到了充分的嬁明。現在我們國 家偉大的融會主義建設事業正在有計割地大規模 展開, 毫無弱問, 廣大的知識分子和利㲘工作者
一定會更加奪發地獻出自己的全部智慧和能力, 努力促進祖國挏會主義建設事業的發展和勝利。 共痤黨和人民政府對一切在科學戰䋨上從事刢浩 性勞動的科學工作者, 將給予一切必要的支持、影 助和鼓跑，中國科學院西北分院箖備委員會也將 盖力協助解决需科學研究工作所必需的設備、經 費和助手等問題, 使科學家有進行科學研究的必 要的條件。我們希望西北地區的科學工作者在共 產黨和人民政府的領導下, 更加親密地團結起來, 不論各個地區、各佔科率門類的科㭗工作者, 也 不論老科學家和青年科學工作者，都應賞親密田 結，互相势助，互相學習，提倡學術上的批評和 自我批訝，克服一切門户之見，發拐集體的智慧，

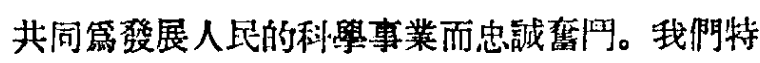
别希望珴們所有的老科學家，要像愛護自己的親

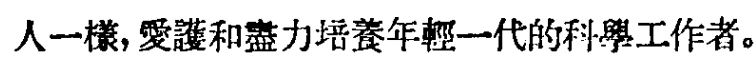

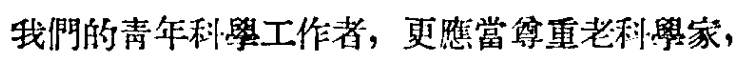

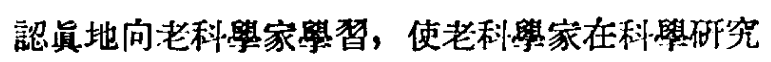
業務上發揮他們高度的積極性和創造性，並樂於 把自己的知識和經騟傳授給下一代。

我們相信，在中國共產黨、中共人民政拊和 偉大領袖毛主席的英明領導下，在中國科學院的

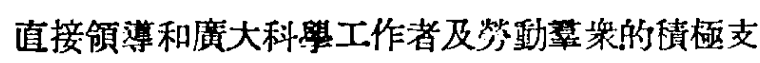
持下，我們是能够勝利地完成開展西北地區科學 研究工作、支援祖國偉大建設的任務的。

\section{[上接 8 真)}

到大致的範图。在這一輪序之下進行科研究, 對科學院西北分院的中心工作和我開舉校培莨研 究人材的任移, 在人力和物力上雙方都可取得相 得益㥿的效果。

以上是西北大學對科學研究的思想情况、淮 借情况以及將來發展的輸绾。篇了保證開展研究 工作得以順利進行, 我們計劃在校內設立㸴究部,

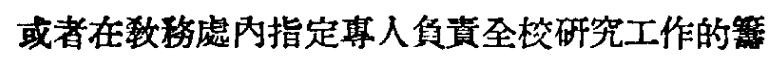
唯, 工作範国包括: 各系研究計劃的案查和研究

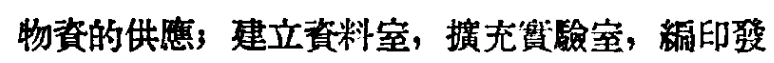
表研究結果的內部刊物; 交流研究經驗, 組織專

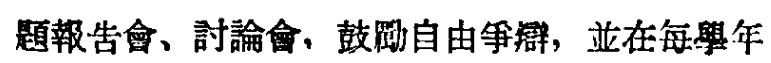
舉行一、二次規模較大的科學討論會。此外，要 給致師們建立研究環境, 適當地安排数學工作, 使 在每週內能有較長的時間可專心從事研究工作。
西北大拏在数眾改革工作上, 由於地區的偏 遠、人力的缺乏, 以及主觀上努力不足, 落後了

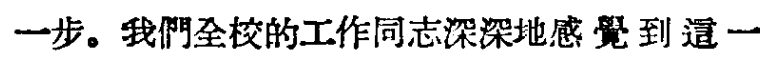
點, 決心急起直追, 趕上這一步, 否則就難以完 成祖國所交付給我們的培食人材的任䅂。領运上

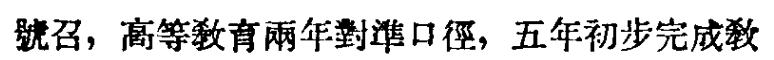
受改革。到了五年之後, 我國已進入第二個五年 計割, 如果屆時数學改革工作仍然落後, 必然留 重影響國家的社會主義建設。科學研究工作在西 北大愁於根基很苃, 落後的可能更大, 我們必 須從早予以更多的注意。西北大學敉師努力倠閏 的票氣是充湤的, 響應政府號召的情 緒是熱烈 的。在黨和政附正確領荨下, 展開科學研究, 對 祖國西北的生產建設做出一些有價值的貢跌, 我 想造是完全可以作到的事。 